\title{
THERMAL, MORPHOLOGICAL AND PASTING PROPERTIES OF BINARY MIXTURES OF STARCHES
}

\author{
Cristina Soltovski de Oliveira ${ }^{1}$, Tiago André Denck Colman², Lucas Waiga ${ }^{1}$, Camila Delinski Bet ${ }^{1}$, Egon Schnitzler ${ }^{*}$ \\ 1 State University of Ponta Grossa - Av. Carlos Cavalcanti, 4748. 84030-900 Ponta Grossa - PR - Brazil \\ ${ }^{2}$ Federal University of Grande Dourados - Rodovia Dourados-Itahum, Km 12, Po Box 364, Dourados, MS 79804-970, Brazil \\ *egons@uepg.br
}

$\begin{array}{ll}\text { Acepted } & 05 / 10 / 2016 \\ \text { Published in } & 01 / 03 / 2017 \\ \end{array}$

Keywords

Starches

Binary mixtures

Thermal analysis

DOI 10.18362/bjta.v6.i1.10

\begin{abstract}
Mixtures of different starches can present similar properties of chemically modified starches, lowering the industrial cost, besides to be an alternative to meet the industrial demand and consumption of natural products. Therefore, this study aims to evaluate the thermal, pasting properties and morphological characterisation of the starches from cassava (Manihot esculenta), sweet potato (Ipomoea batatas) and potato (Solanum tuberosum), in their native form and their binary mixture. The starches were isolated from aqueous method. TG/DTG showed the highest thermal stability for potato starch as well as their mixtures with sweet potato and cassava. DSC values showed that the gelatinisation enthalpy of potato starch was higher than cassava and sweet potato starches and the mixtures of the starches were physical with low chemical interaction. The mixture of cassava and potato starches showed the highest viscosity value. Relative crystallinity values were similar for cassava starch and sweet potato and lower for potato starch. The lowest values for roughness were obtained for cassava starch and their blends. The results obtained for the mixtures of starch showed an average of those values found for starches in their native form.
\end{abstract}

Introduction

Starch is a reserve polysaccharide found in plants, consisting of the mixture of macromolecules of two kinds of aglucan: amylose (about 18-33\%) and amylopectin (about 67$82 \%$ ), present in varying amounts in regard of the botanical source. Both biopolymers consisting of a-D-glucose units connected by $\alpha-1,4$ and $\alpha-1,6$ bonds, the latter linking with the branching of the chains [1].

Amylose is a molecule essentially linear, having occasional branching, while amylopectin is a larger one with about $5-6 \%$ of $\alpha-1,6$ bonds [2]. Starch is present in granules, with different size and shape based on its source. The size of such granule can range from 1-5 $\mu \mathrm{m}$, as seen in rice and amaranth starch, to more than $100 \mu \mathrm{m}$, such as potato starch [3].

In the food industry, starch is utilised as a gelling agent, thickener and as a stabilizer. To attend the technological demand for its application, the starches commonly are chemically modified. However, with the growing demand for natural products, the chemical modifications are losing ground for the physical modifications, such as heat and moisture treatments (HMT) [4].

Mixtures of different starches have been utilised since ancient times in food formulation. The behavior of those mixtures can mimic the properties of chemically modified starches (specially the pasting properties), thus enabling the replacement of more expensive or not so easily available feedstock by the formulation of binary mixtures of low cost starches [5].

With that prospect, this study aims to evaluate the thermal, rheological and structural characterization of the starches from cassava (Manihot esculenta), sweet potato (Ipomoea batatas) and potato (Solanum tuberosum), in their native form and their binary mixture.

Material and Methods

\section{Extraction of starches}

The roots from cassava, sweet potatoes and potatoes were acquired in local commerce of Ponta Grossa - PR. The extraction was performed according to the method of the literature [6] with changes proposed by the authors.

The roots were cleaned, peeled and taken to the blender with water to homogenization. The mass was homogenized and sifted and the white liquid was left to be decanted. The supernatant was discarded and the decanted was placed in an oven with forced air circulation drying for 24 hours at $40{ }^{\circ} \mathrm{C}$. After the starches were drying crushed and stored in a desiccator. 


\section{Binary mixtures of starches}

Each starch (cassava, sweet potato and potato) and the binary mixtures ratios 1:1 of cassava-sweet potato, cassavapotato and potato-sweet potato starches were made totaling 20 grams. The mixtures were placed in appropriate containers and homogenized. Then, each starch and mixture was stored in a desiccator up to constant mass.

\section{Thermal analysis}

Thermogravimetry and derivative
thermogravimetry (TG/DTG)

The instrument DTG-60 System (Shimadzu, Japan) was used to obtain TG/DTG curves. It was preliminarily calibrated with a standard weight and standard calcium oxalate monohydrate. About $5 \mathrm{mg}$ of sample was weighed in alumina crucibles. The heating rate was $10^{\circ} \mathrm{C} \mathrm{min}^{-1}$, and the analysis was performed under a flow of air of $100 \mathrm{ml} \mathrm{min}^{-1}$. All percentages mass losses were determined using TA - 60WS data analysis software [7].

\section{Differential Scanning Calorimetry (DSC)}

The differential scanning calorimeter was used to obtain the DSC curves and the instrument was a DSC model Q200 (T.A. Instr. Ltd.- USA). A 4:1 (water:starch w/w) mixture was prepared and maintained for $25 \mathrm{~min}$ in order to equilibrate the moisture content. The aluminum crucibles were sealed and carried out in order to study the gelatinisation process. The curves were performed and recorded in the instrument software under an air flow of $50 \mathrm{~mL} \mathrm{min-1}$. The temperature range was 20 $100^{\circ} \mathrm{C}$, heating rate of $10^{\circ} \mathrm{C} \mathrm{min}-1$, the instrument was previously calibrated using Indium $99.99 \%$ purity, m.p. $=156.6^{\circ} \mathrm{C}, \Delta H=$ $28.56 \mathrm{~J} \mathrm{~g}^{-1}[8]$.

\section{Pasting properties}

The pasting properties of starches samples were obtained using a viscometer RVA-4 (Newport Sci.,- Australia). For the analysis the suspension was made with $3 \mathrm{~g}$ of starch $(6 \%$ moisture) in $25 \mathrm{~g}$ of distilled water, which was subjected to a controlled heating and cooling cycle under constant shear, where it was held at $50^{\circ} \mathrm{C}$ for $2 \mathrm{~min}$, heated from 50 to $95^{\circ} \mathrm{C}$ at $6{ }^{\circ} \mathrm{C}$ $\mathrm{min}^{-1}$, and held at $95^{\circ} \mathrm{C}$ for $5 \mathrm{~min}$, cooled to 50 at $6^{\circ} \mathrm{C} \mathrm{min}^{-1}$ and held at $50^{\circ} \mathrm{C}$ for $2 \min [9]$.

\section{Morphological study}

\section{X-ray diffraction (XRD)}

The diffraction patterns were obtained using a X-ray diffractometer model Ultima 4 (Rigaku, Japan), employing CuKa radiation $(\lambda=1,5418 \AA)$ and settings of $40 \mathrm{kV}$ and $20 \mathrm{~mA}$. The scattered radiation was detected in the angular range of $5-50^{\circ}$ $(2 \theta)$, with a scanning speed of $8^{\circ} \mathrm{min}^{-1}$ and a step of $0.06^{\circ}$. The Equation 1 was used to calculate the degree of relative crystallinity, following the method described in the literature [10]:

$$
X_{c}=\frac{A p}{(A p+A b)} \times 100 \quad \text { (Equation 1) }
$$

Where $X_{c}$ refers to degree of relative crystallinity; $A p$ refers to the crystalline area on the $X$-ray diffractogram and $A b$ refers to the amorphous area on the X-ray diffractogram.

\section{Atomic force microscopy (AFM)}

The images of the samples were obtained with an Atomic Force Microscope model SPM - 9600 (Shimadzu). About $1 \mathrm{~g}$ of starch was compacted forming a tablet then analyzed by microscope. The images were generated with the aid of SPM Manager version 3.03 software for Windows [11].

\section{Results and discussion}

\section{Thermal analysis}

Thermogravimetry and derivative
thermogravimetry (TG/DTG)

All samples showed curve profiles TG/DTG typical for starch, with three main mass losses. Based on the literature, suggests that the first mass loss is attributed to dehydration, followed by a thermal stability of the anhydrous starch and around $300{ }^{\circ} \mathrm{C}$ starts decomposition and oxidation of organic matter in two mass loss steps, respectively.

These main stages of thermal decomposition occur according to Figure 1.
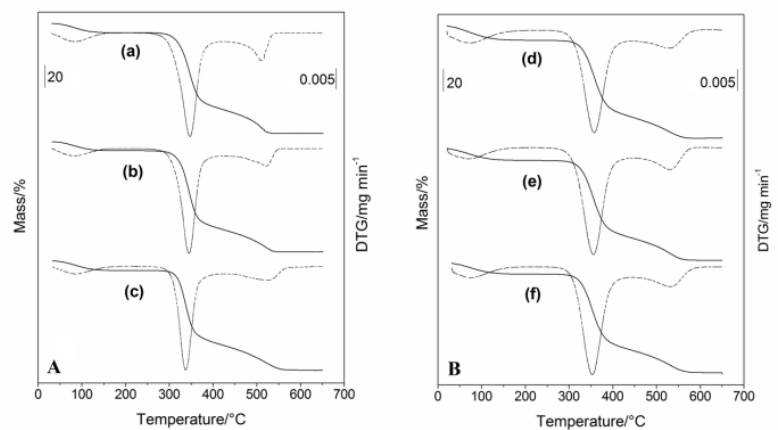

Figure 1: TG and DTG curves: (a) native cassava starch, (b) native sweet potato starch, (c) native potato starch and TG and DTG curve B: (d) cassava starch with potato starch, (e) cassava starch with sweet potato starch and (f) potato starch with sweet potato starch.

Table 1 shows the results of TG/DTG native starches of cassava (a), sweet potato (b) and potato (c). The samples showed similar behaviour in both mass losses. 
Braz. J. Therm. Anal. Vol. 6 No. 1

Table 1: TG and DTG results of: (a) native cassava starch, (b) native sweet potato starch, (c) native potato starch, (d) cassava starch with potato starch, (e) cassava starch with sweet potato starch and (f) potato starch with sweet potato starch.

\begin{tabular}{|c|c|c|c|c|}
\hline \multirow{2}{*}{ Samples } & \multicolumn{2}{|c|}{ TG Results } & \multicolumn{2}{|c|}{ DTG Results } \\
\hline & Step & $\Delta m / \%$ & $\Delta T /{ }^{\circ} \mathrm{C}$ & $T p /{ }^{\circ} \mathrm{C}$ \\
\hline \multirow{4}{*}{ (a) } & $1^{\text {st }}$ & 8.32 & $30-155$ & 82.79 \\
\hline & stability & - & $155-265$ & - \\
\hline & $2^{\text {nd }}$ & 69.26 & $265-423$ & 346.91 \\
\hline & $3^{\text {rd }}$ & 21.50 & $423-581$ & 509.85 \\
\hline \multirow{4}{*}{ (b) } & $1^{\text {st }}$ & 7.98 & $30-157$ & 82.73 \\
\hline & stability & - & $157-277$ & - \\
\hline & $2^{\text {nd }}$ & 71.34 & $277-425$ & 344.70 \\
\hline & $3^{\text {rd }}$ & 19.72 & $425-583$ & 520.88 \\
\hline \multirow{4}{*}{ (c) } & $1^{\text {st }}$ & 8.67 & $30-160$ & 86.29 \\
\hline & stability & - & $160-289$ & - \\
\hline & $2^{\text {nd }}$ & 68.18 & $289-426$ & 337.36 \\
\hline & $3^{\text {rd }}$ & 22.04 & $426-588$ & 522.60 \\
\hline \multirow{4}{*}{ (d) } & $1^{\text {st }}$ & 12.77 & $30-164$ & 73.00 \\
\hline & stability & - & $164-274$ & - \\
\hline & $2^{\text {nd }}$ & 67.68 & $274-439$ & 357.28 \\
\hline & $3^{\text {rd }}$ & 19.51 & $439-598$ & 528.17 \\
\hline \multirow{4}{*}{ (e) } & 1 st & 10.64 & $30-166$ & 69.26 \\
\hline & stability & - & $166-275$ & - \\
\hline & $2^{\text {nd }}$ & 69.41 & $275-446$ & 355.41 \\
\hline & $3^{\text {rd }}$ & 19.41 & $446-592$ & 530.15 \\
\hline \multirow{4}{*}{ (f) } & $1^{\mathrm{st}}$ & 10.12 & $30-168$ & 74.63 \\
\hline & stability & - & $168-272$ & - \\
\hline & $2^{\text {nd }}$ & 68.64 & $272-448$ & 352.50 \\
\hline & $3^{\text {rd }}$ & 19.73 & $448-598$ & 531.26 \\
\hline
\end{tabular}

The results of TG/DTG showed that in general the mixtures have a higher resistance to temperature attributed to the presence of potato starch.

\section{Differential Scanning Calorimetry (DSC)}

DOI 10.18362/bjta.v6.i1

The DSC of mixtures presented a profile with more open endothermic events similar the sum of gelatinisation events of native starches, thus suggesting a physical mixture between samples with little chemical interaction between the mixtures.

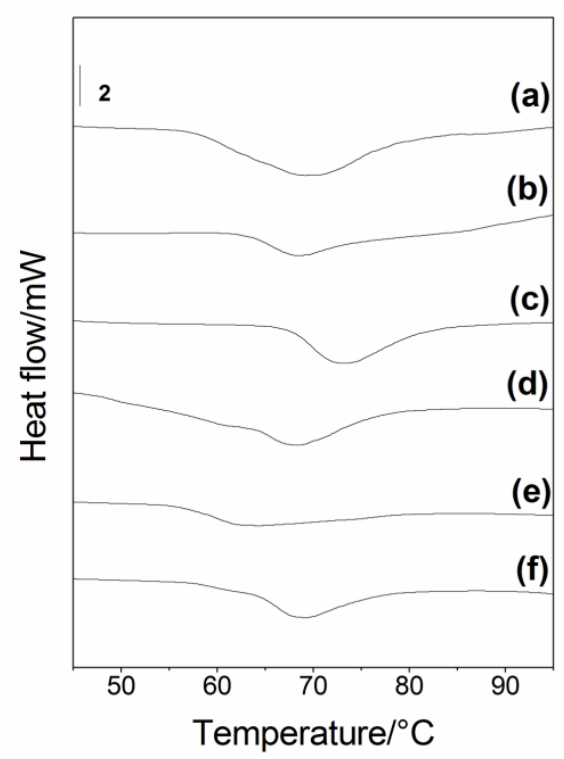

Figure 2: DSC gelatinisation curves: (a) native cassava starch, (b) native sweet potato starch, (c) native potato starch, (d) cassava starch with potato starch, (e) cassava starch with sweet potato starch and (f) potato starch with sweet potato starch.

The DSC results (Table 2) showed that the gelatinisation enthalpy of potato starch was higher $(14.72 \mathrm{~J} / \mathrm{g})$ than cassava $(10.74 \mathrm{~J} / \mathrm{g})$ and sweet potato $(11.08 \mathrm{~J} / \mathrm{g})$ starches and these values are consistent with reported in the literature [10, 12-15].

Table 2: DSC gelatinization, NC-AFM and XRD of (a) native cassava starch, (b) native sweet potato starch, (c) native potato, (d) cassava starch with potato starch, (e) cassava starch with sweet potato starch and (f) potato starch with sweet potato starch.

\begin{tabular}{|c|c|c|c|c|c|c|c|}
\hline \multirow[t]{2}{*}{ Samples } & \multicolumn{4}{|c|}{ DSC gelatinisation } & \multicolumn{2}{|c|}{ AFM } & \multirow{2}{*}{$\begin{array}{c}\text { XRD } \\
\begin{array}{c}\text { Degree of relative } \\
\text { cristallinity }\end{array} \\
\end{array}$} \\
\hline & To/ $\mathrm{C}$ & $T p /{ }^{p C}$ & $T C /{ }^{\circ} \mathrm{C}$ & $\Delta H_{\text {gel }} / \mathrm{J} \cdot \mathrm{g}^{-1}$ & $d_{a} / \mu \mathrm{m}$ & $r_{\mathrm{a}} / \mathrm{nm}$ & \\
\hline (a) & $54.46 \pm 0,03^{f}$ & $64,67 \pm 0.02^{d}$ & $72.3 \pm 0.26^{f}$ & $10.74 \pm 0.32^{\mathrm{d}}$ & $12.41 \pm 1.27^{b}$ & 301.22 & $21.28 \pm 0.34^{b}$ \\
\hline (b) & $57.24 \pm 0.02^{c}$ & $64.04 \pm 0.04 \mathrm{e}$ & $74.77 \pm 0.01^{\mathrm{e}}$ & $11.08 \pm 0.09^{c}$ & $11.82 \pm 3.76^{b}$ & 382.96 & $23.41 \pm 0.21^{\mathrm{a}}$ \\
\hline (c) & $64.18 \pm 0.01^{a}$ & $68.97 \pm 0.02^{b}$ & $76.86 \pm 0.04 c$ & $14.72 \pm 0.12^{\mathrm{a}}$ & $28.13 \pm 3.7^{a}$ & 1015.00 & $16 \pm 0.28 \mathrm{e}$ \\
\hline (d) & $54.68 \pm 0.01 \mathrm{e}$ & $67.92 \pm 0.03 c$ & $76.26 \pm 0.53^{d}$ & $7.68 \pm 0.06 \mathrm{e}$ & $14.04 \pm 5.24 b$ & 301.19 & $17.32 \pm 0.18^{d}$ \\
\hline (e) & $55.26 \pm 0.01^{d}$ & $62.46 \pm 0.03^{f}$ & $79.94 \pm 0.15^{a}$ & $10.92 \pm 0.09 \mathrm{~cd}$ & $10.57 \pm 3.73^{b}$ & 418.13 & $19.88 \pm 0.25^{c}$ \\
\hline (f) & $62.73 \pm 0.02^{b}$ & $69.44 \pm 0.04^{a}$ & $79.37 \pm 0.03^{b}$ & $14.39 \pm 0.05^{b}$ & $9.72 \pm 3.47^{b}$ & 392.05 & $17.10 \pm 0.14^{d}$ \\
\hline
\end{tabular}

$\left(^{*}\right) T_{0}$ "onset" initial temperature, $T p$ peak temperature, $T_{c}$ "endset" conclusion temperature, $\Delta H_{\text {gel }}$ gelatinisation enthalpy, $\left(d_{a}\right)$ Average diameter, $\left(r_{a}\right)$ Average roughness, the degree of crystallinity was calculated as a percentage, peaks are determined in $2 \theta$

Averages followed by the same letters in the same column do not differ statistically by Tukey's test $(P<0.05)$ 
The size of the granules can also influence the gelatinisation temperatures where smaller granules provide higher temperature of gelatinisation. Temperatures and enthalpies of gelatinisation are changed by the form and composition of the granule, distribution of small and large granules, and the sources of starches which may contain different amounts of amylose, amylopectin and phosphate [16].

\section{Viscosity study}

The RVA curves are shown in Figure 3 . It was observed that the potato starch showed the higher viscosity peak (5997 cP) and sweet potato starch showed lower viscosity peak $(1318.5 \mathrm{cP})$. The starch from cassava presented a peak of 4479 $\mathrm{CP}$. The final viscosity had the same behavior for the three starches, below the main peak values.

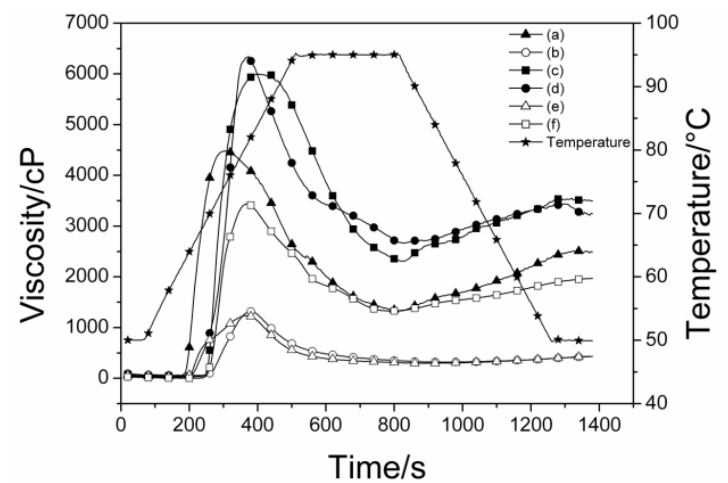

Figure 3: RVA curves: (a) native cassava starch, (b) native sweet potato starch, (c) native potato starch, (d) cassava starch with potato starch, (e) cassava starch with sweet potato starch and (f) potato starch with sweet potato starch.

In agreement with the literature [17] the gelatinisation peak of potato was $4927 \mathrm{cP}$ and cassava $1769 \mathrm{cP}$ under conditions similar to this study. This behavior can be attributed to the fact that the potato starch swell rapidly above the gelatinization temperature, so the peak viscosity was higher.

For mixtures the results shown in average values with respect to those obtained for native starches that form each mixture.

\section{Morphological analysis}

\section{X-ray diffraction (XRD)}

Table 2 shows the results of XRD. The relative crystallinity values were similar for cassava starch and sweet potato, and lower for potato starch. Typically, starches have low crystalline structure and their XRD patterns exhibit similar profile. The region of granule with more intense peaks corresponds to amylopectin [18]. The values of relative crystallinity are in agreement with those described in the literature $[9,19]$.

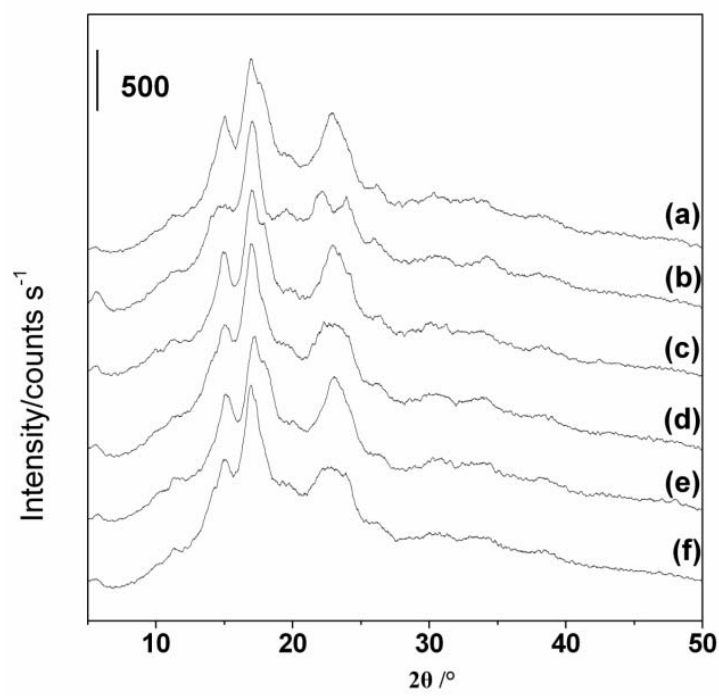

Figure 4: X-ray difratograms of: (a) native cassava starch, (b) native sweet potato starch, (c) native potato starch, (d) cassava starch with potato starch, (e) cassava starch with sweet potato starch and (f) potato starch with sweet potato starch.

The XRD patterns of the samples are characteristic of $B$ type starches with main peaks at $5.6^{\circ}, 15^{\circ}, 17^{\circ}, 18^{\circ}$ and $23^{\circ}$

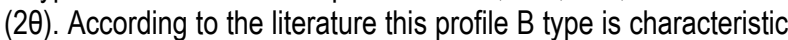
of starches from roots and tubers $[18,20]$.

Table 3: RVA results of: (a) native cassava starch, (b) native sweet potato starch, (c) native potato starch, (d) cassava starch with potato starch, (e) cassava starch with sweet potato starch and (f) potato starch with sweet potato starch.

\begin{tabular}{ccccccc}
\hline Samples & Pasting temperature ${ }^{\circ} \mathrm{C}$ & $\begin{array}{c}\text { Viscosity } \\
\text { peak/cP }\end{array}$ & Peak time/sec & Setback/cP & Break/cP & Final viscosity/cP \\
\hline (a) & $62.08 \pm 0.32^{\mathrm{b}}$ & $4479.00 \pm 1.41^{\mathrm{c}}$ & $305 \pm 0.99^{\mathrm{e}}$ & $1167.50 \pm 2.12^{\mathrm{b}}$ & $\begin{array}{c}3152.50 \pm 2.12 \\
\mathrm{c}\end{array}$ & $2488.50 \pm 9.99^{\mathrm{c}}$ \\
(b) & $70.01 \pm 0.28^{\mathrm{a}}$ & $1318.50 \pm 0.71^{\mathrm{e}}$ & $378 \pm 2.55^{\mathrm{b}}$ & $110.50 \pm 2.12^{\mathrm{f}}$ & $\begin{array}{c}1001.00 \pm 1.41 \\
\mathrm{e}\end{array}$ & $428.00 \pm 1.41 \mathrm{e}$ \\
(c) & $68.53 \pm 0.32^{\mathrm{b}}$ & $5997.00 \pm 2.83^{\mathrm{b}}$ & $398 \pm 2.97^{\mathrm{a}}$ & $1193.50 \pm 7.78^{\mathrm{a}}$ & $\begin{array}{c}3689.00 \pm 2.83 \\
\mathrm{a}\end{array}$ & $3501.50 \pm 7.78^{\mathrm{a}}$ \\
(d) & $64.48 \pm 0.25^{\mathrm{c}}$ & $6336.50 \pm 2.12^{\mathrm{a}}$ & $374 \pm 2.97 \mathrm{~b}^{\mathrm{c}}$ & $579.00 \pm 5.66^{\mathrm{d}}$ & $\begin{array}{c}3665.50 \pm 9.19 \\
\mathrm{~b}\end{array}$ & $3242.00 \pm 9.19^{\mathrm{b}}$ \\
(e) & $63.93 \pm 0.04^{\mathrm{c}}$ & $1230.50 \pm 2.12^{\mathrm{f}}$ & $362 \pm 2.97^{\mathrm{d}}$ & $135.50 \pm 0.71^{\mathrm{e}}$ & $\begin{array}{c}935.50 \pm 2.12^{\mathrm{f}} \\
430.50 \pm 0.71^{\mathrm{e}}\end{array}$ \\
(f) & $68.73 \pm 0.04^{\mathrm{b}}$ & $3537.50 \pm 0.71^{\mathrm{d}}$ & $370 \pm 2.97^{\mathrm{c}}$ & $639.50 \pm 2.12^{\mathrm{c}}$ & $\begin{array}{c}2112.50 \pm 3.54 \\
\mathrm{~d}\end{array}$ & $1698.50 \pm 3.54^{\mathrm{d}}$ \\
\hline
\end{tabular}

(") cP "centipoises", sec "seconds". Averages followed by the same letters in the same column do not differ statistically by Tukey's test $(P<0.05)$ 


\section{Atomic force microscopy (AFM)}

Figure 5 shows a larger size for potato starch granule compared to the granules of cassava starch and sweet potato. The higher surface roughness was obtained for potato starch granules, which was confirmed by the data presented in Table 2 .
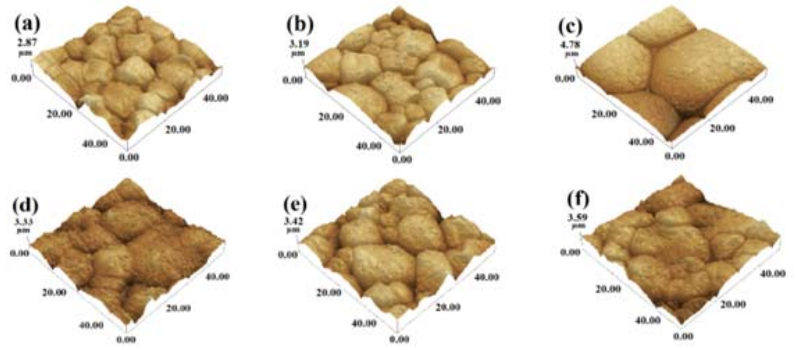

Figure 5: Micro-images for: (a) native cassava starch, (b) native sweet potato starch, (c) native potato starch, (d) cassava starch with potato starch, (e) cassava starch with sweet potato starch and (f) potato starch with sweet potato starch.

The results presented in Table 2 showed a significant difference in average roughness and average diameter between the potato starch granules and the cassava and sweet potato starches. Both the average diameter as the average roughness of cassava starch and sweet potatoes were very similar, while the potato starch showed value nearly three times higher in these measures.

The mixtures had granules of various sizes, similar to those of native starch granules present in each mixture, suggesting a physical mixture between each species.

\section{Conclusion}

The results of thermal analysis showed for the TG/DTG that the potato starch obtained the highest thermal stability, followed by sweet potato starch and cassava respectively, as well as mixtures containing potato starch were also more thermally stable. The DSC showed higher gelatinization enthalpy for potato starch, followed by cassava and sweet potato starch, respectively. The profile of the DSC curves suggests that the mixture of the starch was physical with low chemical interaction. Rheological and structural characterization of the samples suggests the formation of physical mixtures, with relative crystallinity values and size of granules intermediaries between native starch values constituting the sample.

\section{References}

[1] Waterschoot J, Gomand SV, Fierens, E, Delcour JA. Starch blends and their physicochemical properties. Starch/Stärke, 2015:67:1-13.

[2] Ai Y, Jane J-L. Gelatinization and rheological properties of starch. Starch/Stärke, 2014:67:213-224.

[3] Lindeboom N, Chang PR, Tyler RP. Analytical, biochemical and physicochemical aspects of starch granule size, with emphasis on small granule starches, a review. Starch/Stärke, 2004:56:89-99.

[4] Arns B, Bartz J, Radunz M, Evangelho JA do, Pinto VZ, Zavareze, ER, Dias ARG. Impact of heat-moisture treatment on rice starch, applied directly in grain paddy rice or in isolated starch. LWT - Food Sci Technol, 2015:60:708-713.

[5] Waterschoot J, Gomand SV, Delcour JA, Goderis B. Direct evidence for the non-additive gelatinization in binary starch blends: A case study on potato starch mixed with rice or maize starches. Food Hydrocolloids, 2015:50:137-144.

[6] Bello-Pérez LA, García-Suárez FJ, Méndez-Montealvo G, Nascimento JRO, Lajolo FM, Cordenunsi BR.Isolation and characterization of starch from seeds of Araucaria brasiliensis: a novel starch for application in food industry. Starch-Stärke, 2006:58:283-291.

[7] Hornung PS, Granza AG, Oliveira CS, Lazzarotto M, Schnitzler E. Study of the effects of ultraviolet light and sodium hypochlorite solutions on properties of cassava starch granules. Food Biophys. 2015:10:368-374

[8] Oliveira CS, Andrade MMP, Colman TAD, Costa FJOG, Schnitzler E. Thermal, structural and rheological behaviour of native and modified waxy corn starch with hydrochloric acid at different temperatures. J Therm Anal Calorim, 2014:115:13-18.

[9] Beninca C, Colman TAD, Lacerda LG, Filho MASC, Bannach $G$, Schnitzler E. The thermal, rheological and structural properties of cassava starch granules modified with hydrochloric acid at different temperatures. Thermochim Acta, 2013:552:6569.

[10] Colman TDA, Demiate IM, Schnitzler E. The effect of microwave radiation on some thermal, rheological and structural properties of cassava starch. J Therm Anal Calorim 2014:115:2245-2252.

[11] Lacerda LG, Filho MASC, Bauab T, Demiate IM, Colman TDA, Andrade MMP, Schnitzler E. The effects of heat-moisture treatment on avocado starch granules. J Therm Anal Calorim, 2015:120:387-393

[12] Torruco-Uco J, Betancur-Ancona D. Physicochemical and functional properties of makal (Xanthosoma yucatanensis) starch. Food Chem, 2007:101:1319-1326.

[13] Zhu F, Yang X, Cai Y-Z, Bertoft E, Corke $H$. Physicochemical properties of sweet potato starch. Starch/Stärke, 2011:63:249-259,

[14] Lu Z-H, Donner E, Yada RY, Liu Q. Impact of $\gamma$-irradiation, CIPC treatment, and storage conditions on physicochemical and nutritional properties of potato starches. Food Chem, 2012:133:1188-1195. 
[15] Donovan JW, Lorenz K, Kulp K. Differential scanning of heat-moisture treated wheat and potato starches. Cereal Chem, 1983:6:381-387.

[16] Yonemoto PG, Calori-Domingues MA, Franco CL. M.; Efeito de tamanho dos grânulos nas características estruturais e físicoquímicas de amido de trigo. Cienc Tecnol Aliment, 2008:27:761771.

[17] Mishra S, Rai T. Morphology and functional properties of corn, potato and tapioca starches. Food Hydrocoloids, 2006:20:557-566.
[18] Lacerda LG, Filho MASC, Demiate IM, Bannach G, lonashiro $M$, Schinizler $E$. Thermal behaviour of corn starch granules under action of fungal a-amylase. . J Therm Anal Calorim, 2008:93:445449 .

[19] Alberton C, Colman TAD, Souza JA de, Oliveira CS, Andrade MMP, Schnitzler E. Thermal analysis, rheology, X-Ray difractometry and atomic force microscopy in the evaluation of binary mixtures of "starch-hidrocolloids". J Microbiol Biotechn Food Scien, 2014:3:305-309.

[20] Hoover R. Composition, molecular structure and phisicochemical properties of tuber and root starches: a review. Carbohyd Polym, 2001:45:253-267. 